\title{
WHAT ARE INTERPRETATIVE STRATEGIES?
}

\author{
Ernst M Conradie \\ Department of Religion and Theology \\ University of the Western Cape
}

\section{Introduction}

This contribution provides a closer investigation of the so-called "spiral of interpretation" as identified in the "hermeneutical map" of Biblical interpretation that was analysed in the contribution of Jonker in this volume. ${ }^{1}$

The notion of a "spiral of interpretation" describes the way in which the meaning, significance, value, use or relevance of Biblical texts is appropriated in and for ever-changing contemporary contexts. The emphasis is therefore not on a reconstruction of the interaction between a text and a particular historical context (i.e. in Biblical times) in the past, but on a creative construction of meaning from a point of departure (or return!) in the text. The aim is not a dogged repetition of the content of the Biblical texts but on contemporary praxis, on a renewed response to the text in the lives of Biblical interpreters. The emphasis is not on "what the text has meant", but on "what the text means", for us, today. ${ }^{2}$

There are different ways in which the final outcome of the reading process may be described. In hermeneutical literature concepts such as a "fusion of horizons" (Gadamer), a "second naïveté" (Ricoeur), recontextualisation (Croatto), the "response" of the reader, the "pleasure of the text" (Barthes) and "transforming Biblical reading" have been used in this regard. The question remains the same though: How are Biblical texts being used, applied and appropriated today? How do contemporary interpreters develop innovations of the tradition of interpretation of the Biblical texts in and for changing circumstances (whether personal or communal, local or global)?

In response to this question, the argument of this contribution will proceed in the following way:

- An analysis of various (relatively crude) interpretative strategies,

- A discussion of various attempts to offer a more sophisticated description of the spiral of interpretation,

- The crucial role of "doctrinal keys",

- The role of interpretative trajectories.

\section{Interpretative strategies based on direct forms of application}

The notion of interpretative strategies should not be confused with exegetical methods or with the wide range of approaches to Biblical interpretation. ${ }^{3}$ Interpretative strategies refer to the ways in which readers establish a link between some aspects in the Biblical text and

1. On the notion of interpretative strategies, with some illustration and practical exercises, see also Conradie \& Jonker (2001:69-76).

2. The distinction between "what the text has meant" and "what the text means" has often been criticised. Clearly, it is impossible to reconstruct what the text has meant in another period without contemporary appropriations of the relevance of the text influencing such a reconstruction. Likewise, a contemporary appropriation of the meaning of the text assumes a view on the origin and content of the text. However, despite these observations, the attempt to reconstruct an earlier appropriation of the text, as far as this is possible, remains a valid historical exercise.

3. See Conradie et al (1995) for an overview of such "approaches" to Biblical hermeneutics. 
some aspects in the world in which they live. The notion of interpretative strategies should therefore be understood in a somewhat technical sense: it refers to the "techniques" used by readers to overcome the (historical) distance between the text and a contemporary context. The question is how this appropriation takes place in the world of the reader.

Although the notion of reading or interpretative strategies is often used in literature on Biblical hermeneutics, specific "strategies" are very seldom described or analysed in any detail. In recent South African literature, the following attempts to clarify the notion of interpretative strategies may be mentioned:

\subsection{Rossouw's contribution}

Towards the end of an important article ${ }^{4}$ in the very first edition of Scriptura, Hennie Rossouw identified three basic interpretative strategies:

An archaeological strategy in which the archai, the principia, the stable or eternal truths of the Biblical texts are uncovered by extracting it from its historical packaging. These truths are directly applied to the contemporary context because their validity is precisely regarded as being timeless. In the context of everyday Biblical interpretation such a strategy is typically expressed in the format of "We must remember that ..."; or "I learned today that ..."

An analogical-typological strategy in which analogies between a situation described in the Biblical text and the contemporary context are identified. The concrete, historical context is emphasised in both instances. These two contexts are not identical but certain typical situations can indeed be identified. The life story of the contemporary interpreter is, for example, regarded as a sequel to the story of the characters in the Biblical texts. In the context of everyday Biblical interpretation such a strategy is typically expressed in the format of "I also experience ... in my life."

An eschatological-critical strategy in which the contemporary fulfilment of a future promised in the text is investigated. On the one hand, these promises provide hope and inspiration to live in expectation of the fulfilment of God's promises. On the other hand, these promises function in a critical way because they still challenge any all too easy acquiescence in the imperfections of the world in which we live. ${ }^{5}$ In the context of everyday Biblical interpretation such a strategy is typically expressed in the format of "God is encouraging / challenging / warning / reassuring me that ...".

\subsection{The analysis in Fishing for Jonah}

In section B of Fishing for Jonah, I have analysed these three strategies identified by Rossouw somewhat further. ${ }^{6}$ In each case, I have distinguished between a relatively crude and a relatively more sophisticated version of these interpretative strategies (with illustrations from the book of Jonah). The following nine readings strategies emerged from this analysis: ${ }^{7}$

Group 1: Statements of abiding validity are identified in the text:

Eternal truths about God, humanity and the world are systematically extracted from the text and applied directly in the present-day context.

4. See Rossouw (1980).

5. Rossouw (1980:24-28).

6. See also Conradie \& Jonker (2001:70-75) for a simplified version of my earlier analysis.

7. See Conradie et al (1995:44-56) for a more detailed discussion. 
The text is regarded as a body of historical or even scientific information that may be of interest to people today (a cruder form of -a-).

Eternal moral principles, ones that still apply in the contemporary context, are identified in the text.

Commands found in the text are carried out literally in the contemporary context (a cruder form of -b-).

\section{Group 2: Similarities (amidst differences) between text and context are identified:}

Analogies are discovered between the situation described in the text and the contemporary context. Thus one can identify with the situation in the Bible and with the message that applied at that time.

Any particular aspect in the text is used as a pretext to reflect on the same aspect in the contemporary context (a cruder form of -e-).

\section{Group 3: The meaning of the text is applied and appropriated in a different way in the new context:}

Certain of God's promises are identified in the text: these may be fulfilled anew in each new context.

A text is understood as a prediction of something that is about to happen for the first time now, in the contemporary context (a cruder form of -g-).

The Holy Spirit directly imparts God's will to the faithful in the contemporary context with the aid of some springboard in the text (compare with -f-).

What is the difference between a relatively crude and a relatively adequate interpretation? In each of these strategies some form of similarity between text and context is identified. With this in mind the following characteristics of relatively adequate interpretation as opposed to relatively crude interpretation may be identified:

- It is based on more than one similarity between text and context and therefore takes more variables into account. The similarity or similarities are not marginal aspects of the text or the context. It goes to the heart of what the text is concerned with. It involves both text and context as wholes.

- It also takes cognizance of the differences between text and context and does not try to transpose the message of the text directly onto the contemporary context.

- An adequate interpretation is indeed concerned with the "otherness" of the text, with the way the text can have a transforming influence on the contemporary context. It also contributes to a better understanding of the contemporary context in the light of the similarities and differences between text and context.

\subsection{Classic interpretative strategies}

In retrospect, one may argue that some of the classic schools of interpretation also offer such interpretative strategies. They have enabled earlier interpreters to make the meaning of the Biblical text relevant and accessible at a time when the meaning of the text had already become obscure (or embarrassing). This applies to the following strategies: ${ }^{8}$

Allegorical interpretation (perhaps a variation on Rossouw's archeological approach?);

8. See, e.g. the discussion in Deist \& Burden's An ABC of Biblical exegesis, (1980:51-83). 
The "fourfold" method (a variation on the allegorical approach);

Typological interpretation (perhaps a variation on Rossouw's analogical-typological approach?);

The "pesher" method of interpretation;

"Pearls on a string" (see the discussion of quoting proof texts below).

Another well-known form of Biblical interpretation also provides its own peculiar interpretative strategy (in the more technical sense of the word): Biblicism.

The aim of this strategy is one of repetition. An attempt is made to restate the content of certain values, morals or beliefs by following, repeating or applying the content of Biblical texts as directly as possible. In practice, this is of course not quite possible and users of this strategy therefore often resort to the strangely similar one of quoting proof texts (see below).

\subsection{Quoting proof texts}

Interpretative strategies refer to the ways in which a link between the Biblical text and contemporary context is established. In most of the above-mentioned strategies this link is established from a point of departure in the text. This seems to assume a movement from text to context (i.e. following a "deductive" approach). By contrast, "inductive" or "centrifugal" interpretations of the Bible focus on the contemporary context. The questions, needs and problems identified within a particular context are taken as a point of departure to bridge the gap between text and context. This stimulates a search for adequate "answers" in the Bible and in the Christian tradition. ${ }^{9}$

The interpretative strategy of quoting proof texts assumes a point of departure in the history of interpretation. It usually articulates a link between text and contexts that were established previously within a particular tradition of interpretation. This previously established link would be the product of a complex interplay between the "wirkungsgeschichte" of the Bible, (a) specific Christian tradition(s) and a whole range of factors in the contemporary context. In terms of the interpretative strategy of quoting proof texts, the interpreter returns to the Biblical texts in order to scrutinise them for evidence that would support, supplement, defend, test or develop this particular view. In this way the Bible provides "proof texts" for such a view. ${ }^{10}$

This strategy is often used in a very crude way by simply quoting Biblical phrases verbatim, assuming that this quotation provides a valid "proof" for the particular view. The historical context, genre and literary context of the text are often ignored completely. It should be noted, though, that the interpretative strategy of quoting proof texts may also be used in a more sophisticated way, and with reference to a thorough exegesis of Biblical texts. Such exegesis may be offered to support a particular theological point of view. The strategy of quoting proof texts may even be regarded as unavoidable for constructive theological contributions in the sense that Biblical interpreters always draw on a particular pre-understanding and often try to find support for their views in the Biblical texts. Indeed, this approach correlates with what Thomas Kuhn would describe as "normal science".

The Biblical texts may in this way be used (and abused) to provide support for a wide

9. For this (admittedly only relative) distinction between deductive and inductive approaches to Biblical interpretation, see Conradie et al (1995:33-35) as well as Conradie \& Jonker (2001:85-86).

10. See the critical comments by Smit (1991) on the interpretative strategies employed by reformed systematic theologians in the Netherlands and in South Africa. 
variety of views on an equally wide variety of issues, e.g. doctrines (cf. the use of dicta probantia), morals, views on reality, science, social customs, history, politics, or economics.

\subsection{Conclusion}

Three further brief comments on the use of such interpretative strategies are important:

a) The analysis of these strategies may provide the necessary conceptual tools for further empirical research. It is indeed possible to identify the strategy or strategies used in specific sermons, Bible study groups, meditations, etc. This is especially true when explicit attempts are made to apply the meaning of a text in and for a contemporary context.

b) In concrete examples of Biblical interpretation more than one of these strategies are often employed. For empirical research, it will be necessary to identify the dominant strategies in such cases.

c) The analysis of these strategies remains somewhat crude. Even the more sophisticated strategies seem to presuppose that the reading and interpretation of the Bible will lead to more or less direct applications of the meaning of a specific Biblical text in the lives of interpreters. The aim of the act of interpretation is to identify a specific implication of the text for contemporary Christian praxis. The relatively crude strategies base this implication on a single point of similarity between text and contemporary context (e.g. "Jonah bought a ticket to Tarsish; we also buy tickets in our lives, perhaps for many invalid purposes"). The very attempt to identify a "strategy" or "technique" seems to suggest such a relatively more direct form of Biblical interpretation.

A closer analysis may reveal that relatively adequate Biblical interpretations are far more sophisticated than such a strategy or technique could possibly allow. Biblical interpretation is more of an art than a technique that can be described in terms of strategies.

\section{Biblical interpretation as a modification in the "world" of the interpreter}

Each of the strategies that were discussed above is an attempt to apply the meaning of a specific Biblical text in a particular way in the contemporary context. In their more crude forms they tend to "jump" immediately from the text to the context. In this way they often "bypass" or even ignore the influence of the Christian tradition (its institutions, practices, doctrines and values) on Biblical interpretation. It is assumed that the influence of doctrine on the interpretation process only leads to biased interpretation. The relevance of Biblical Studies for Practical Theology is ascertained without the help (or hindrance?) of Systematic Theology.

To avoid such crude interpretative strategies, a more "indirect" approach may be proposed. The somewhat romantic Gadamerian notions of interpretation as a "fusion of horizons", a "playful game" or a "conversation" suggest, for example, that the "world" of the interpreter is transformed in any new act of interpretation in a dialectic way. Unfortunately, Gadamer refuses to provide a more detailed (for him too technical) account of how such a fusion of horizons takes place.

I propose that a closer investigation of the impact of an act of interpretation on the "world" of the interpreter may be helpful towards a clearer understanding of the notion of interpretative strategies.

A description of the "world" of the interpreter may draw on a wide range of analyses in philosophy, sociology of knowledge, anthropology and cognitive psychology. The 
following (somewhat arbitrary) list of concepts have been used to describe this "world" of the interpreter (whether an individual, a group or a larger community):

- horizons (Gadamer)

- interpretative frameworks

- worldviews (also "Lewens- en wêreldbeskouings")

- "paradigms" (Kuhn)

- cosmological narratives (Thomas Berry)

- "conviction sets" (McClendon \& Smith)

- "fiduciary frameworks" (Polanyi)

- "grand narratives" (Lyotard)

- "symbolic universes" (Berger \& Luckmann)

- "forms of life" or "language games" (Wittgenstein)

- "epistemes" (Foucault)

- "world-construction" (Gordon Kaufman)

- "large, overarching, communal vocabularies" (Rorty)

- the "basic grammar" (e.g. doctrines) of communities understood from a "culturallinguistic" point of view (Lindbeck)

- the "closure" resulting from more or less rigid "frames" introduced within the play of difference in a differential network or loose web of signs (deconstruction)

- "constellations" (see Richard Bernstein's use of the term)

- a "Gestalt" in one's field of observation (Gestalt psychology)

These concepts are used within very different contexts and also have very different connotations (which are sometimes constructive and sometimes more pejorative). Nevertheless, this list of concepts may have one thing in common: they all express a way of (socially) organising an otherwise diffuse field into a relatively more integrated and coherent whole. They therefore enable an interpreter to make sense of a given field. They suggest a more (or less) comprehensive "framework" that is more (or less) rigid or stable and more (or less) totalising.

For present purposes, the notion of the "world" of the interpreter may simply be used. The interpreting subject may be either an individual or a community (e.g. a Bible study group). This interpretative "world" organises a whole range of experiences, objects (including persons, material possessions, buildings, texts, etc), geographical orientations, social relationships, social institutions, economic conditions, cultural customs, psychological predispositions, habits, values, preferences, priorities, commitments, beliefs, convictions, expectations, etc, etc. into a structured whole.

One way of understanding the "world" of the interpreter is to describe it in terms of a cluster of vectors, i.e. any experiences, values, beliefs, customs, habits, preferences, etc. playing a role in the world of the interpreter. These vectors differ from one another in terms of their relative strength and exercise this power in different directions. In the organisation of this "world" of the interpreter, these vectors may be structured hierarchically. Some vectors may be closer to the centre and others closer to the periphery.

The role of the unifying (unum facere, to make something one) centre is to create some form of unity in the world of the interpreter, and thus to reduce the degree of cognitive dissonance. The centre often reveals some internal tensions. Sometimes there may emerge clear divisions within this interpretative world (e.g. in the case of unresolved dualisms). 
Although the "world" of the interpreter has an integrative function such integration is never fully accomplished. Such comprehensive integration (e.g. in the case of closed systems) may even lead to a certain sterility in the interpretative world.

The boundaries of the cluster of vectors are often somewhat loose but may become (at least temporally) fairly rigid in order to protect the interpreter's identity whenever necessary. The cluster of vectors will, for the sake of avoiding too much cognitive dissonance, usually remain reasonably stable. At the same time, the organising centre and the boundaries also have to remain sufficiently flexible to be able to respond to changing circumstances and new challenges.

This world of the interpreter is constantly being adapted as a result of new experiences and the full range of social, political, economic, philosophical and religious variables. New experiences (including reading experiences) should be understood as new vectors that may "stir" (interact, strengthen, reinforce, clash with, undermine) some of the other vectors. If a new experience proves to be powerful, it may even restructure a (smaller) cluster of vectors. A major adaptation to the organising centre would constitute something like a religious conversion. A new experience may, on the other hand, also fade away into insignificance. In this way, new experiences are absorbed into the cluster of vectors. The constellations and hierarchies in this world of the interpreter are therefore not stable and may be influenced by new experiences.

Any new experiences are temporarily highlighted through the focus of attention of the interpreter on these vectors. These vectors dominate the consciousness of the interpreter temporarily although other vectors may undermine this primacy subconsciously.

The reading of texts like the Bible may be regarded as one example of such an experience. Whenever a text is read particular beliefs, values, habits, attitudes, priorities and interests in the world of the interpreter will be highlighted. This becomes possible through a conscious or subconscious identification of the similarities and differences between the new experience and the existing cluster of vectors in the world of the interpreter. The identification of similarities usually reinforces the current structuring of vectors. The identification of sharp differences will always pose a challenge. If this challenge is rejected, this will lead (temporarily) to more rigid boundaries. If this challenge is accepted, a more (or less) dramatic adaptation to the structure of vectors will be required.

For example, when a person is reading the parable of the Good Samaritan, the person does not necessarily have to identify any direct application of the meaning of the text (despite the good intentions of some). ${ }^{11}$ The reading experience may well highlight the importance of the virtue of charity in the world of the interpreter though. This virtue will then move closer to the centre and will thus become important for determining a response to any new experiences later encountered by the interpreter. The reading experience may therefore influence the world of the interpreter (a person, group or community) in a systemic and highly significant way even though no direct "applications" derived from the particular reading experience may be forthcoming.

This analysis allows for a far more sophisticated understanding of the impact of Biblical texts on the world of the interpreter, especially if compared to the relatively rigid and sometimes crude interpretative strategies that were described above.

11. A more direct response may indeed be required in other cases, e.g. when one reads instructions from one's employer. 


\section{The role of doctrinal keys in Biblical interpretation}

One of the most intriguing aspects of theological interpretation is the very possibility of relating Biblical texts in all their plurality and ambiguity with an equally complex contemporary context.

David Tracy has suggested that this is de facto possible through the power of what he calls an analogical imagination. ${ }^{12}$ Interpretation can only take place when some analogies, that is, similarities-amidst-differences, are identified, in the case of theological interpretation between the Biblical texts, the Christian tradition and a contemporary context. Tracy (with Paul Ricoeur) refers to the classic axiom of Aristotle in this regard: "To spot the similar in the dissimilar is the mark of poetic genius" ${ }^{13}$ The ability to identify these similarities, and to express them in an accessible form (image), is based on the power of the imagination. ${ }^{14}$

The identification of such similarities does not take place in a coincidental way. Such similarities are discovered through long-standing theological traditions that have formulated and developed the necessary conceptual tools to facilitate this process. I propose that certain heuristic keys in the world of the interpreter play an important role in this regard.

Heuristic keys are typically based on the dominant beliefs, doctrines, values, customs, and habits of interpretive communities. They are not directly derived from either the Biblical texts or the contemporary world but are precisely the product of previous attempts to construct a relationship between text, tradition and context. Since such heuristic keys usually coincide with some of the dominant theological motifs within a particular context, it may be helpful to specify such heuristic keys as doctrinal keys.

Doctrinal keys have a double function in theological interpretation. They provide a key to unlock both the meaning of the contemporary context and of the Biblical texts. They therefore (and simultaneously) enable the interpreter also to establish a link between text and contemporary context. Doctrinal keys are not only employed to find similarities but to construct similarities, to make things similar (idem-facere), if necessary. ${ }^{15}$ The scope of such doctrinal keys is often quite comprehensive: they purport to provide a clue to the core meaning of the contemporary context as a whole and the Biblical text as a whole. The dangers of simplification and a far-reaching harmonising of differences in an analysis of both the Bible and the contemporary context are quite apparent. However, this may be inescapable since any act of interpretation requires the identification of some form of similarity-in-difference.

The following well-known examples of such comprehensive doctrinal keys may be mentioned: the victory over the powers of death (Eastern orthodox), justification by faith alone (Lutheran), the kingdom of God (Calvin), sin-grace (Augustine), nature-grace (Thomas), the imitation of Christ (Thomas a' Kempis), the notion of a new covenant,

12. See Tracy (1981).

13. Tracy (1981:410).

14. For an in-depth analysis of the notion of an "analogical imagination", emphasising the identification and imaginative expression of analogies, see Conradie (1992).

15. According to Ricoeur (1978:148), the creation of metaphorical meaning does not only involve the identification of existing similarities. It also involves an association of semantic fields that have hitherto been considered as quite different from one another. It is thus necessary to make these semantic fields similar:

But we miss entirely its semantic role if we interpret it in terms of the old association by resemblance ... The assimilation consists precisely in making similar, that is, semantically proximate, the terms that the metaphorical utterance brings together. 
Christian love and charity, the incarnation, the cross-resurrection dialectic, the ongoing work of the Spirit, the gifts of the Spirit (the charismatic movement), the duty of Christians as "prophets, kings and priests", liberation from oppression, ecological wholeness, mission and witness, hope, etc. In each case, a particular doctrinal key not only provides an explanation of the historical meaning of the Biblical texts; it also provides the parameters for contemporary Christian living in the continued presence of God.

This proposal may be illustrated with the example of "liberation from oppression": When this doctrinal key is used, the Bible is read to find support for the notion that the God of the Bible is, in a special way, a God who cares for and liberates the poor and oppressed. This soon becomes a strategy to read the Bible as a whole, i.e. to identify this as a persistent theme throughout the plurality of Biblical texts. At the same time "liberation for the oppressed" may also be used to highlight the most salient features of a contemporary context, e.g. as a context of desperate poverty, oppression and marginalisation, a world in need of God's liberation. The message follows clearly: the same God of the Bible is still present to liberate the poor and oppressed in their present circumstances.

This doctrinal key thus provides a strategy to establish a link between text and context. When such a doctrinal key is used persistently and pervasively, a plurality of connotations is likely to be associated to, in the above-mentioned example, the notion of "liberation." This would call for a systematic clarification of this particular doctrinal key and its relationship with other core Christian symbols. ${ }^{16}$ Inevitably, it becomes the contribution of Christian (systematic) theology to provide such a clarification and perhaps also an imaginative reconstruction of the content of such doctrinal keys.

One implication of this analysis is that it is simply not possible to "jump" from the Biblical text to a specific problem in the contemporary context without the use of such doctrinal keys. While some interpreters may prefer to avoid or even to resist traditional doctrinal distinctions at all costs, newly constructed doctrines surface in emerging theological traditions through the persistent use of heuristic keys. ${ }^{17}$ This analysis therefore confirms the pervasive, if often highly ambiguous influence of Christian doctrine and values in the process of Biblical interpretation.

Three further comments on the role of doctrinal keys are important here:

a) The identification of the role of these doctrinal keys may clarify the often rather diffuse use of the word "hermeneutics". It is often employed to describe the results of a particular interpretation of the Bible - instead of a theory of interpretation (i.e. at a metalevel). It has, for example, become customary to talk about a feminist hermeneutics, a "black hermeneutics of liberation" an "ecological hermeneutics" or even a reformed, Pentecostal, African or a Lutheran hermeneutics. Technically, these uses of the concept hermeneutics do not indicate a new or a different theory of interpretation but refer to the use of specific doctrinal keys, e.g. "the oppression of women", "liberation for the poor and oppressed," "the struggle of the black working class" or the "need to re-appropriate traditional African customs". A discussion of the implications of the use of such keys for an adequate understanding of text, tradition and context usually forms an integral

16. The dominant doctrinal keys of an interpretive community may sometimes remain hidden, unarticulated, taken for granted. Any attempt to define these may even be regarded as sacrilegious since the meaning should be "obvious" to everyone. To mention one example: I have argued elsewhere (Conradie 1993) that there is a tendency in Gerald West's work, Biblical hermeneutics of liberation (1991), to ontologise and absolutise the notion of "liberation". It thus becomes self-explanatory, all-inclusive, and mystified.

17. The replacement of former doctrines by new heuristic keys based on the doctrines of emerging theological traditions is again well illustrated by West's (1991) use of the notion of "liberation". 
part of such an analysis.

b) These examples make it clear that doctrinal keys have both a constructive and an ideology-critical function. They enable interpreters to identify and construct the meaning of the text (and the context) but they also provide a tool to evaluate the available evidence and to unmask (in terms of that particular perspective) any distortions in the process of interpretation (in the world behind the text, the world of the text, the history of interpretation of the text and the contemporary context).

c) The choice of doctrinal keys will necessarily (by definition) lead to a distortion of both text and context. Such distortions may well be ideological in the pejorative sense of the word. A hermeneutics of suspicion towards the use of heuristic keys is therefore of the utmost importance. However, this is hampered by the pervasiveness of heuristic keys because they also influence the selection of ideology-critical tools. Heuristic keys prescribe to their users what they should be suspicious about.

\section{The role of trajectories}

Doctrinal keys are used, transmitted, amplified and refined in interpretative communities and through long-standing theological traditions. Any new act of interpretation may be regarded as a further extrapolation of some of the trajectories in such a tradition.

The notion of trajectories and the role of doctrinal keys in a particular theological trajectory call for some further reflection.

a) Walter Brueggemann's article on trajectories in the Old Testament represents perhaps the most well-known use of this notion. ${ }^{18}$ Brueggemann's analysis is rooted in the tradition history approach to text production. Two features of this approach are important for the present analysis: 1) The emphasis on a particular stable social location in which a trajectory is developed (e.g. a particular local shrine). 2) The emphasis on one particular symbol which becomes the root metaphor for theological reflection at that particular social location (e.g. the house of David, the law of Moses, the exodus, the temple). A trajectory is constituted when the same symbol is continuously being reinterpreted in the same social location in and for changing circumstances.

b) Brueggemann analyses two dominant trajectories in the literature shaped and energised by the Mosaic and Davidic covenants: i) the trajectory of "Mosaic liberation" which emerged in an early Israelite peasant revolt, in the Mushite priesthood of Shilo and Nob, in prophetic critiques, in the Deuteronomistic circle and in the displaced Levitical priesthood after the exile. ii) The "royal consolidation" trajectory surfaced in the Davidic-Solomomic state coup, in the Aaronid priesthood of Hebron and Jerusalem, the institutions of the monarrchy and the Priestly writings and in the post-exilic Zadokite priesthood. $^{19}$

c) In several recent articles Klaus Nürnberger followed a somewhat similar approach that also traces the development of certain "trajectories". ${ }^{20} \mathrm{He}$ focused on soteriological trajectories, i.e. the memory of certain redemptive experiences which becomes a "soteriological paradigm" for a subsequently evolving tradition. Nürnberger cites the following examples of such soteriological paradigms: the promise to the patriarchs, exodus and conquest, the divine order established by the rule of kings, covenant and

18. Brueggemann (1993).

19. Brueggemann (1993).

20. See Nürnberger (1992, 1993, 1994, 1997). 
law, creation and eschatological transformation, priesthood and sacrifice.

In an article on the "royal paradigm," Nürnberger traces, for example, different notions of political rule in the history of Israel, in the New Testament era and throughout the history of the Christian tradition. He shows how this trajectory has, at times, been influenced by new theological insights but that these insights were distorted through ideological legitimation in subsequent times. Nürnberger then extrapolates this trajectory to reflect on the notion of democracy in the contemporary South African context. $^{21}$ In an essay on eschatology Nürnberger follows a similar approach. He traces developments and distortions in the notion of hope throughout the history of the JewishChristian tradition and extrapolates these developments towards a contemporary Christian eschatology. ${ }^{22}$

A few features of Nürnberger's approach are important. Although he does not use the notion of trajectories explicitly, there is a clear attempt to trace historical developments. He does not focus on a particular social location nor on a particular symbol but on a particular theme or problem to which people in different social locations, using different root metaphors responded. He shows how aberrations of a trajectory occurred within the canonical texts but also how these aberrations where often redirected in subsequent developments. The Biblical canon is regarded as a primal and prototypical period in the history of a larger tradition that includes further deliberations in the history of Christian doctrine. ${ }^{23}$

The extrapolation of these traditions is in both cases crucial. The task of contemporary interpretation is not to select texts that can be appropriated (directly?) within contemporary contexts. Instead, the task of interpretation involves an attempt to trace the history of a trajectory carefully (in all its aberrations and innovations) in order to identify the direction or underlying thrust of its developments, and, on that basis, to extrapolate this dynamic towards the future. Nürnberger comments:

The hermeneutical cycle should not focus, therefore, on the translation of a particular text into a particular situation, but on extrapolating the dynamic and direction of the evolutionary process of a soteriological paradigm or tradition into present constellations of need. ${ }^{24}$

d) The value of the notion of hermeneutical trajectories is that it puts the use of heuristic keys in a historical perspective. It emphasises that the world of interpretive communities is dynamic and is continually being transformed through the process of ongoing interpretation. It has to be remembered, however, that the very identification of a trajectory remains a construction by contemporary scholars that can never do full justice to the plurality of voices in the Biblical canon. Although the task of selecting, prioritising and organising these voices (into a trajectory) is unavoidable and necessary, it remains open to ideological abuse and the danger of coercing marginalised voices.

e) But what does this act of extrapolation really entail? The notion of extrapolation suggests both an element of continuity and of critical innovation in a trajectory. Such extrapolation indeed requires something like an analogical imagination. Interpreters have to identify some aspects of the tradition that could be built upon in order to address

21. See Nürnberger (1992).

22. Nürnberger (1994).

23. See Nürnberger (1992:17): "The rationale of the closure of the canon was to demarcate a primal and prototypical period of evolutionary history, which could act as a criterion for the acceptability of subsequent developments."

24. Nürnberger (1992:17). 
the needs and questions of a present context. The notion of analogy allows for a rich range of possibilities where the new interpretation may reinforce, refine, draw implications from, adapt, challenge, or conflict with existing beliefs and practices.

These analogies have to be expressed in a concrete material form which will be accessible within the particular context. There are no clear-cut rules for an act of extrapolation. It requires both an in-depth understanding of the tradition and the imagination to construct new, creative interpretations. It requires the prophetic ability to read the "signs of the time" and speak an appropriate word for a particular context. It requires a priestly consciousness to find an appropriate way of living in the presence of God in changing circumstances.

\section{Conclusion}

These comments again show that interpretation cannot be reduced to a recipe, strategy or clear-cut method. It remains a form of art, a skill that can only be acquired and appreciated through experience. An adequate method or strategy of interpretation does not guarantee adequate interpretation. The adequacy of interpretations can only be discerned post facto.

It is not particularly helpful to follow the "correct" procedure, method or strategy to arrive at a given interpretation. The origin of a given interpretation (and the methods used in the process) is of less importance (the best methods are also fallible). It is far more important to allow for a process of thorough critical testing in which as many critical questions as possible may be raised. ${ }^{25}$ 


\section{BIBLIOGRAPHY}

Brueggemann, W 1993. Trajectories in Old Testament literature and the sociology of ancient Israel. In: Gottwald, NK \& Horsley, RA 1993. The Bible and liberation. Political and social hermeneutics. Maryknoll: Orbis Books.

Conradie, EM 1992. Review Article: Biblical hermeneutics of liberation. Modes of reading the Bible in the South African context of liberation by Gerald O West (Pietermaritzburg: Cluster Publications). Journal of Theology for Southern Africa 85, 61-65.

Conradie, EM 1992. What is an analogical imagination? The South African Journal of Philosophy 11:4, 103-112.

Conradie, EM et al 1995. Fishing for Jonah. Various approaches to Biblical interpretation. Study Guides on Religion and Theology 1. Bellville: UWC Publications.

Conradie, EM \& Jonker, LC 2001. Angling for interpretation. A guide to understand the Bible better. Study Guides in Religion and Theology 4. Bellville: University of the Western Cape.

Deist, FE \& Burden, JJ 1980. An ABC of Biblical exegesis. Pretoria: JL van Schaik.

Nürnberger, K 1992. The royal-imperial paradigm in the Bible and the modern demand for democracy. Journal of Theology for Southern Africa 81, 16-34.

Nürnberger, K 1993. The God of Abraham, Isaac and Jacob: The trajectory of a soteriological paradigm in Biblical times. Scriptura 46, 1-23.

Nürnberger, K 1994. Towards a new heaven and a new earth. In: De Gruchy, JW \& VillaVicencio, C (eds) 1994. Doing theology in context. South African perspectives, 139151. Cape Town: David Philip.

Nürnberger, K 1997. The conquest of chaos: The Biblical paradigm of creation and its contemporary relevance. Journal of Theology for Southern Africa 98, 45-63.

Ricoeur, P 1978. The rule of metaphor. London: Routledge and Kegan Paul.

Rossouw, HW 1980. Hoe moet 'n mens die Bybel lees? Die hermeneutiese probleem. Scriptura 1, 7-28.

Smit, DJ 1991. Wat beteken 'die Bybel sê'? 'n Tipologie van leserskonstrukte. Hervormde Teologiese Studies 47:1, 167-185.

Tracy, DW \& Grant, RM 1984. A short history of the interpretation of the Bible.2 Philadelphia: Fortress Press, 151-187.

Tracy, DW 1981. The analogical imagination: Christian theology and the culture of pluralism. London: SCM Press.

West, GO 1991. Biblical hermeneutics of liberation. Modes of reading the Bible in the South African context. Pietermaritzburg: Cluster Publications. 